
\title{
28 Research Square \\ Effects of intraoperative fluid management on postoperative outcomes after pericardiectomy
}

\author{
Likui Fang \\ Hangzhou Red Cross Hospital \\ Hong Zheng \\ Hangzhou Red Cross Hospital \\ Wenfeng Yu \\ Hangzhou Red Cross Hospital \\ Gang Chen \\ Hangzhou Red Cross Hospital \\ Fangming Zhong ( $\square$ fangming574330@163.com ) \\ Hangzhou Red Cross Hospital
}

\section{Research}

Keywords: intraoperative fluid management, constrictive pericarditis, pericardiectomy

Posted Date: December 29th, 2020

DOl: https://doi.org/10.21203/rs.3.rs-135234/v1

License: (c) (1) This work is licensed under a Creative Commons Attribution 4.0 International License. Read Full License 


\section{Abstract}

Background The effects of intraoperative fluid management on the patients with constrictive pericarditis undergoing pericardiectomy remain unclear. This study explored the relationship between intraoperative fluid management and postoperative outcomes in these patients.

Methods We retrospectively studied 92 patients with constrictive pericarditis undergoing pericardiectomy and assigned them to the restrictive group and the liberal group according to the intraoperative total fluid infusion rate. Postoperative outcomes were compared between the two groups. Binary logistic regression analysis was performed to determine the relationship between the intraoperative total fluid infusion rate and postoperative outcomes.

Results There were $46(50.0 \%)$ cases in the restrictive group (2.68 to $7.46 \mathrm{ml} / \mathrm{kg} / \mathrm{h}$ ) and $46(50.0 \%)$ cases in the liberal group ( 7.47 to $20.55 \mathrm{ml} / \mathrm{kg} / \mathrm{h}$ ). Compared with the liberal group, the restrictive group had significantly lower incidences of postoperative complications and cardiac complications ( $P=0.005$ and $\mathrm{P}=0.006$, respectively). Binary logistics regression analysis also showed the increased risks of postoperative complications $(\mathrm{OR}, 3.551 ; 95 \% \mathrm{Cl}, 1.192-10.580 ; \mathrm{P}=0.023)$ and cardiac complications (OR, $5.083 ; 95 \% \mathrm{Cl}, 1.206-21.426 ; \mathrm{P}=0.027)$ at the liberal group. In addition, the restrictive group had shorter postoperative hospital stay $(P=0.026)$ in comparison to the liberal group.

Conclusion In patients with constrictive pericarditis undergoing pericardiectomy the intraoperative total fluid infusion rate was significantly associated with postoperative outcomes. Restrictive fluid management strategy could exert positive effects on enhanced recovery after surgery and might be the preferred intraoperative fluid management policy.

\section{Introduction}

Constrictive pericarditis is a rare disease with poor prognosis[1]. The inelastic pericardium leads to impaired filling and diastolic dysfunction[2]. The etiology of constrictive pericarditis varies widely. In developing countries, tuberculosis is the major cause; in developed countries, the most frequent causes are idiopathic, post-cardiac surgery and post radiation[3,4]. Constrictive pericarditis is chronic and progressive in a majority of cases[4]. As a result, most patients eventually develop diastolic heart failure and need surgical pericardiectomy[5]. Although pericardiectomy is the most effective approach to relieve the pericardial constriction, it is accompanied with high incidence of postoperative complications and inhospital mortality[6].

Disordered hemodynamics is a common complication after pericardiectomy and a major cause of inhospital death[7, 8]. The status of hemodynamics is significantly associated with fluid management which exerts great influence in perioperative course. Optimal fluid management is able to enhance the recovery after surgery and improve postoperative outcomes[9], but the evidence in pericardiectomy is limiting. This study aimed to explore the effect of intraoperative fluid management on postoperative 
outcomes and find an optimum range of the intraoperative fluid infusion rate in the patients with constrictive pericarditis.

\section{Methods}

\section{Study population}

We retrospectively reviewed the records of the patients diagnosed as constrictive pericarditis in our department between November 2012 and June 2020. The patients were excluded if they were not performed pericardiectomy or if the data of intraoperative fluid infusion was missing. The patients with history of cardiac surgery and renal failure were also excluded. Finally, a total of 92 patients were enrolled. Their perioperative characteristics including demographic, intraoperative, and outcomes data were extracted from the hospital electronic medical records system. The study protocol was approved by the Institutional Review Board of Hangzhou Red Cross Hospital.

The preoperative diagnosis of constrictive pericarditis mainly depended on the clinical symptoms, echocardiographic findings, chest enhanced computed tomography and central venous pressure (CVP). CVP was measured by percutaneous internal jugular vein puncture. Pericardial constriction was considered if CVP was higher than $15 \mathrm{cmH}_{2} \mathrm{O}$. Pericardiectomy was routinely performed by median sternotomy in all patients without the use of cardiopulmonary bypass. The extent of pericardiectomy included at least the anterolateral pericardium between the two phrenic nerves, the basal pericardium over the diaphragmatic surface, the pericardium on the great arteries and the pericardium from superior vena cava-right atrium junction to inferior vena cava-right atrium junction.

\section{Exposure Variable}

The exposure variable was the intraoperative total fluid infusion rate. The volume of intraoperative total fluid was collected from the anesthesia record and defined as the volumes of crystalloid, colloid, and blood products administered between initiation of anesthesia care and arrival in the postanesthesia care unit[10]. The crystalloid was Ringer solution and the colloid was hydroxyethyl starch. The intraoperative total fluid infusion rate $(\mathrm{ml} / \mathrm{kg} / \mathrm{h})$ was defined as the intraoperative total fluid volume per kilogram of weight divided by the operation duration.

\section{Outcomes}

The primary outcome was the incidence of postoperative complications, including cardiac complications, pulmonary complications and acute liver or kidney injury. Postoperative complications were defined as the comorbidities that occurred after surgery but did not exist before. Cardiac complications included low cardiac output, cardiac failure and arrhythmia. Pulmonary complications included acute respiratory distress syndrome, pneumonia, atelectasis and pulmonary embolism. Acute liver injure was defined as the total bilirubin concentration $\geq 3.0 \mathrm{mg} / \mathrm{dL}$ or the alanine aminotransferase level $\geq 350 \mathrm{U} / \mathrm{L}$. Acute kidney injury was defined as an increase in serum creatinine by at least $0.3 \mathrm{mg} / \mathrm{dL}$ or $50 \%$ from 
preoperative levels within 48 hours postoperatively or the existence of an acute kidney injury diagnostic code within 7 days postoperatively[11]. Second outcomes were postoperative intensive care unit (ICU) stay, postoperative intubation, duration of using vasoactive agents, duration of chest drainage, postoperative hospital stay and in-hospital mortality

\section{Statistical analysis}

The correlation between the intraoperative total fluid infusion rate and postoperative complications was analyzed by the receiver operating characteristic (ROC) curve and the optimal cutoff value of intraoperative total fluid infusion rate was determined by calculating the Youden Index. The enrolled patients were divided into the restrictive group and the liberal group according to the cutoff value. The measurement data of the two groups were statistically analyzed with the t-test. The $\chi 2$ test, the corrected $\chi 2$ test or the Fisher exact test was used for the enumeration data, depending on the actual situation. Binary logistic regression analyses were performed to determine the relationship between the intraoperative total fluid infusion rate and postoperative outcomes. Confounders were included, based on univariate analysis. These analyses were conducted using SPSS software (version 24.0, IBM SPSS Inc. United States). Statistical significance was set at $\mathrm{P}$ value $<0.05$ (all $\mathrm{P}$ values presented were two-sided).

\section{Results}

\section{Group division}

The result of ROC curve showed that the intraoperative total fluid infusion rate statistically correlated with postoperative complications. The area under curve (AUC) was $0.638(95 \% \mathrm{Cl}=0.521-0.755, \mathrm{P}=0.029)$ (Figure 1). The Youden Index was further calculated and the result showed the optimal cutoff value of the intraoperative total fluid infusion rate was $7.47 \mathrm{ml} / \mathrm{kg} / \mathrm{h}$ (sensitivity $69.7 \%$, specificity $61.0 \%$, Youden Index 0.307 ). According to the cutoff value, the patients were divided into the restrictive group and the liberal group. In the restrictive group, the range of intraoperative total fluid infusion rate was from 2.68 to $7.46 \mathrm{ml} / \mathrm{kg} / \mathrm{h}$ (median=5.99). In the liberal group, the range was from 7.47 to $20.55 \mathrm{ml} / \mathrm{kg} / \mathrm{h}$ (median=9.45).

\section{Baseline characteristics}

A total of 92 patients were enrolled in this study, with 46 (50\%) cases in the restrictive group and 46 (50\%) cases in the liberal group. Table 1 presented the comparative results of baseline characteristics between the two groups. There were no significant differences in gender, age, etiology, symptom duration, preoperative comorbidities, cardiac function, ASA classification, blood pressure, left ventricular ejection fraction (LVEF), preoperative lactate and preoperative brain natriuretic peptide (BNP) between the two groups. Comparing with the liberal group, the restrictive group had higher body mass index (BMI) $(P=0.003)$ and preoperative CVP $(=0.029)$ and longer operative duration $(P<0.001)$. No blood products were transfused in any of the study patients during pericardiectomy. 


\section{Postoperative outcomes}

The comparison of outcomes between the restrictive group and the liberal group was shown in the Table 2. Compared with the liberal group, the restrictive group had significantly lower incidences of postoperative complications and cardiac complications ( $\mathrm{P}=0.005$ and $\mathrm{P}=0.006$, respectively). By contrast, there were no statistical differences in the incidences of pulmonary complications and acute liver or kidney injury between the two groups. In addition, the restrictive group had shorter postoperative hospital stay $(P=0.026)$ in comparison to the liberal group. There was no in-hospital mortality in the two groups.

\section{Multivariate analysis}

In order to determine the degree of contribution of the intraoperative total fluid infusion rate on postoperative outcomes and cardiac complications, we performed univariate analysis at first and then included the statistically significant factors in multivariate regression model (Supplemental Table 1 and 2). Because nearly one third of the patients had only crystalloid during the surgical procedure, the infusion rate of intraoperative total fluids in these patients was the intraoperative crystalloid infusion rate, so this was excluded in the regression model.

Binary logistic regression analysis demonstrated that compared with the restrictive group, the risk for postoperative complications was significantly increased in the liberal group (OR, 3.551; $95 \% \mathrm{Cl}, 1.192-$ 10.580; $P=0.023$ ). Similarly, the risk for cardiac complications was also increased in the liberal group (OR, $5.083 ; 95 \% \mathrm{Cl}, 1.206-21.426 ; \mathrm{P}=0.027)$.

\section{Discussion}

In constrictive pericarditis, heart diastolic function is limited due to the thicken and inelastic pericardium, leading to the hemodynamic paradox of low preload but high filling pressures[12]. Conservative treatment is only used as a temporary measure in most cases, and surgical intervention is necessary to relieve the pericardial constriction[13, 14]. However, outcomes after pericardiectomy are generally unfavorable, although they are influenced by preoperative clinical conditions and etiology[14-16]. One of the major complications is disordered hemodynamics which often occurs after surgical pericardiectomy[17]. Because of the myocardial atrophy, acute overdistension of ventricles after dissecting pericardium could lead to cardiac failure, especially in cases of long-standing constriction[3,18]. Additionally, in order to prevent pulmonary edema, the ideal approach is to decorticate the left ventricle before the right ventricle but this is not always technically feasible[19]. In theory, optimal intraoperative fluid management could reduce the risks of acute volume overload, ventricular failure, and pulmonary edema.

With a focus on improving postoperative outcomes, intraoperative fluid management has played an important role in the enhanced recovery after surgery (ERAS) which has been advocated by many surgeons[9]. Extensive comparative studies have been reported in the literature on the intraoperative fluid management in elective non-cardiac surgery. A systematic review and meta-analysis suggested that compared with the liberal fluid policy, the restrictive policy could reduce $35 \%$ risk of postoperative 
complications in elective surgery[20]. In addition, a recent large observational study conducted by Shin, C. $\mathrm{H}$. and his colleagues showed that liberal intraoperative fluid management was associated with increased postoperative complications, length of stay and total cost of hospitalization[11]. Intraoperative fluid management should maintain the patient in a euvolaemic state and excessive fluid has been proven to be associated with more harm in non-cardiac surgery[21].

The elevated burden of mortality and morbidity after cardiac surgery presents a tremendous opportunity for enhanced recovery[22]. Although ERAS is relatively new to cardiac surgery, the evidence-based protocols have shown promise[23]. However, clinically applicable standards for the infusion volume and rate of intraoperative fluid in pericardiectomy have yet to emerge, and anesthesiologists offer a relatively random adjustment during the surgery. This study provides some references to clinical intraoperative fluid management in the patients with constrictive pericarditis undergoing pericardiectomy. The results of our study supported the view that the difference in infusion rate of intraoperative total fluid was associated with significant differences in postoperative outcomes. Our study demonstrated that restrictive fluid infusion rate (2.68 to $7.46 \mathrm{ml} / \mathrm{kg} / \mathrm{h}$ ) was associated with a lower incidence of postoperative complications and cardiac complications but was not linked to an increased risk of acute liver or kidney injury. The incidence of postoperative pulmonary complications was also lower in the restrictive group, but the difference was not statistically significant. Postoperative length of stay was significantly increased in the patients receiving liberal fluid infusion rate, presumably because of the need to treat complications.

This study verified the correlation between postoperative outcomes and intraoperative total fluid infusion rate but there are some limitations. First, because this is a single-center retrospective study, selection bias is inevitable. Second, body mass index and preoperative CVP between groups were uneven, which is related to the grouping variable of fluid infusion rate. Third, because of the complex and variable postoperative conditions after pericardiectomy, postoperative fluid infusion was managed individually and the difference was difficult to be adjusted. This imbalance can only be resolved through a prospective randomized trial. Finally, because only a small fraction of patients received colloid, we were not adequately powered to independently reproduce the association between colloid infusion rate and outcomes. Prospective randomized study is required to demonstrate the influences of different intraoperative colloid infusion rates on mortality and renal failure rate.

\section{Conclusions}

Although the intraoperative period is a relatively brief portion of the perioperative course, it represents a uniquely vulnerable and complex physiologic state. Intraoperative fluid management strategy is an easily modifiable factor that significantly influences postoperative outcomes. This study showed the difference in infusion rate of intraoperative total fluid was associated with significant differences in postoperative outcomes. Restrictive fluid management strategy could exert positive effects on ERAS and might be the preferred intraoperative fluid management policy. 


\section{Abbreviations}

ROC, receiver operating characteristic; AUC, area under curve; NYHA, New York Heart Association; COPD, chronic obstructive pulmonary disease; $\mathrm{MI}$, myocardial infarction; $\mathrm{CAD}$, coronary atherosclerotic heart disease; PVD, peripheral vascular disease; ASA, American society of anesthesiology; BMI, body mass index; SBP, systolic blood pressure; DBP, diastolic blood pressure; CVP, central venous pressure; LVEF, left ventricular ejection fraction; $\mathrm{BNP}$, brain natriuretic peptide; $\mathrm{OR}$, odds ratio; $\mathrm{Cl}$, confidence interval; ERAS, enhanced recovery after surgery;

\section{Declarations}

\section{Acknowledgements}

Not applicable.

\section{Author Contributions}

Drs. Likui Fang and Fangming Zhong contributed to the conception and design of the work. Drs. Likui Fang and Hong Zheng contributed to data analysis and editing the manuscript. Drs. Wenfeng Yu and Gang Chen contributed to data acquisition, statistical analysis and interpretation of the data. Drs. Likui Fang and Fangming Zhong contributed to the revision of the manuscript. All authors have approved the final draft of the manuscript.

\section{Funding}

This study was funded by a traditional Chinese medicine science and technology plan in Zhejiang Province (2019ZB095).

\section{Availability of data and materials}

The datasets used and/or analysed during the current study are available from the corresponding author on reasonable request.

\section{Ethics approval and consent to participate}

The study protocol was approved by the Institutional Review Board of Hangzhou Red Cross Hospital. Because of the retrospective nature of the study and without any specific intervention, the informed consent has been agreed to be waived.

\section{Consent for publication}

Not applicable.

\section{Competing interests}


The authors declare that they have no competing interests

\section{References}

1. Miranda WR, Oh JK. Constrictive Pericarditis: A Practical Clinical Approach. Progress in cardiovascular diseases. 2017;59(4):369-79.

2. Dudzinski DM, Mak GS, Hung JW. Pericardial diseases. Curr Probl Cardiol. 2012;37(3):75-118.

3. Tuck BC, Townsley MM. Clinical Update in Pericardial Diseases. Journal of cardiothoracic and vascular anesthesia. 2019;33(1):184-99.

4. Welch TD. Constrictive pericarditis: diagnosis, management and clinical outcomes. Heart (British Cardiac Society). 2018;104(9):725-31.

5. Adler Y, Charron P, Imazio M, Badano L, Baron-Esquivias G, Bogaert J, et al. 2015 ESC Guidelines for the diagnosis and management of pericardial diseases: The Task Force for the Diagnosis and Management of Pericardial Diseases of the European Society of Cardiology (ESC)Endorsed by: The European Association for Cardio-Thoracic Surgery (EACTS). Eur Heart J. 2015;36(42):2921-64.

6. Gopaldas RR, Dao TK, Caron NR, Markley JG. Predictors of in-hospital complications after pericardiectomy: a nationwide outcomes study. J Thorac Cardiovasc Surg. 2013;145(5):1227-33.

7. Ghavidel AA, Gholampour M, Kyavar M, Mirmesdagh Y, Tabatabaie MB. Constrictive pericarditis treated by surgery. Texas Heart Institute journal. 2012;39(2):199-205.

8. Mutyaba AK, Balkaran S, Cloete R, du Plessis N, Badri M, Brink J, et al. Constrictive pericarditis requiring pericardiectomy at Groote Schuur Hospital, Cape Town, South Africa: causes and perioperative outcomes in the HIV era (1990-2012). J Thorac Cardiovasc Surg. 2014;148(6):3058-65.

9. Makaryus R, Miller TE, Gan TJ. Current concepts of fluid management in enhanced recovery pathways. Br J Anaesth. 2018;120(2):376-83.

10. Wu Y, Yang R, Xu J, Rusidanmu A, Zhang X, Hu J. Effects of Intraoperative Fluid Management on Postoperative Outcomes After Lobectomy. The Annals of thoracic surgery. 2019;107(6):1663-9.

11. Shin CH, Long DR, McLean D, Grabitz SD, Ladha K, Timm FP, et al. Effects of Intraoperative Fluid Management on Postoperative Outcomes: A Hospital Registry Study. Annals of surgery. 2018;267(6):1084-92.

12. Goldstein JA, Kern MJ. Hemodynamics of constrictive pericarditis and restrictive cardiomyopathy. Catheter Cardio Inte. 2020;95(6):1240-8.

13. Khandaker MH, Schaff HV, Greason KL, Anavekar NS, Espinosa RE, Hayes SN, et al. Pericardiectomy vs medical management in patients with relapsing pericarditis. Mayo Clin Proc. 2012;87(11):106270.

14. Murashita T, Schaff HV, Daly RC, Oh JK, Dearani JA, Stulak JM, et al. Experience With Pericardiectomy for Constrictive Pericarditis Over Eight Decades. The Annals of thoracic surgery. 2017;104(3):742-50. 
15. Busch C, Penov K, Amorim PA, Garbade J, Davierwala P, Schuler GC, et al. Risk factors for mortality after pericardiectomy for chronic constrictive pericarditis in a large single-centre cohort. European journal of cardio-thoracic surgery : official journal of the European Association for Cardio-thoracic Surgery. 2015;48(6):e110-6.

16. Nishimura S, Izumi C, Amano M, Imamura S, Onishi N, Tamaki Y, et al. Long-Term Clinical Outcomes and Prognostic Factors After Pericardiectomy for Constrictive Pericarditis in a Japanese Population. Circulation journal : official journal of the Japanese Circulation Society. 2017;81(2):206-12.

17. Lin $Y$, Zhou M, Xiao J, Wang B, Wang Z. Treating constrictive pericarditis in a chinese single-center study: a five-year experience. The Annals of thoracic surgery. 2012;94(4):1235-40.

18. Maisch B, Seferovic PM, Ristic AD, Erbel R, Rienmuller R, Adler $Y$, et al. Guidelines on the diagnosis and management of pericardial diseases executive summary; The Task force on the diagnosis and management of pericardial diseases of the European society of cardiology. Eur Heart J. 2004;25(7):587-610.

19. Depboylu BC, Mootoosamy P, Vistarini N, Testuz A, El-Hamamsy I, Cikirikcioglu M. Surgical Treatment of Constrictive Pericarditis. Texas Heart Institute journal. 2017;44(2):101-6.

20. Schol PB, Terink IM, Lance MD, Scheepers HC. Liberal or restrictive fluid management during elective surgery: a systematic review and meta-analysis. J Clin Anesth. 2016;35:26-39.

21. Gupta R, Gan TJ. Peri-operative fluid management to enhance recovery. Anaesthesia. 2016;71:40-5.

22. Noss C, Prusinkiewicz C, Nelson G, Patel PA, Augoustides JG, Gregory AJ. Enhanced Recovery for Cardiac Surgery. Journal of cardiothoracic and vascular anesthesia. 2018;32(6):2760-70.

23. Engelman DT, Ben Ali W, Williams JB, Perrault LP, Reddy VS, Arora RC, et al. Guidelines for Perioperative Care in Cardiac Surgery: Enhanced Recovery After Surgery Society Recommendations. JAMA surgery. 2019;154(8):755-66.

\section{Tables}

Table 1. Clinical characteristics of the patients based on the intraoperative total fluid infusion rate 


\begin{tabular}{|c|c|c|c|}
\hline Variables & $\begin{array}{l}\text { Restrictive group } \\
(\mathrm{N}=46)\end{array}$ & $\begin{array}{l}\text { Liberal group } \\
(\mathrm{N}=46)\end{array}$ & $\begin{array}{l}\mathrm{P} \\
\text { value }\end{array}$ \\
\hline Gender & & & 0.625 \\
\hline Male & 36 (78.3\%) & $34(73.9 \%)$ & \\
\hline Female & $10(21.7 \%)$ & $12(26.1 \%)$ & \\
\hline Age, years & $56(16-80)$ & $61(17-83)$ & 0.235 \\
\hline Etiology & & & 1.000 \\
\hline Tuberculosis & $43(93.5 \%)$ & $42(91.3 \%)$ & \\
\hline Other & $3(6.5 \%)$ & $4(8.7 \%)$ & \\
\hline Symptom duration, months & $2.0(0.3-18.0)$ & $2.0(0.3-12.0)$ & 0.140 \\
\hline Preoperative NYHA functional class & & & 0.258 \\
\hline$\nabla$ & $4(8.7 \%)$ & $3(6.5 \%)$ & \\
\hline$\nabla$ & $19(41.3 \%)$ & $12(26.1 \%)$ & \\
\hline$\nabla$ & $22(47.8 \%)$ & $27(58.7 \%)$ & \\
\hline$\nabla$ & $1(2.2 \%)$ & $4(8.7 \%)$ & \\
\hline Hypertension & $6(13.0 \%)$ & $9(19.6 \%)$ & 0.397 \\
\hline Diabetes & $3(6.5 \%)$ & $2(4.3 \%)$ & 1.000 \\
\hline Atrial fibrillation & $5(10.9 \%)$ & $8(17.4 \%)$ & 0.369 \\
\hline COPD & $1(2.2 \%)$ & 0 & 1.000 \\
\hline Previous MI & 0 & 0 & / \\
\hline CAD & $2(4.3 \%)$ & $3(6.5 \%)$ & 1.000 \\
\hline PVD & $2(4.3 \%)$ & $4(8.7 \%)$ & 0.673 \\
\hline Previous stroke & 0 & $2(4.3 \%)$ & 0.475 \\
\hline ASA classification & & & 1.000 \\
\hline 1 & 0 & 0 & \\
\hline 2 & $14(30.4 \%)$ & $14(30.4 \%)$ & \\
\hline 3 & $31(67.4 \%)$ & $31(67.4 \%)$ & \\
\hline 4 & $1(2.2 \%)$ & $1(2.2 \%)$ & \\
\hline $\mathrm{BMI}, \mathrm{kg} / \mathrm{m}^{2}$ & $21.7(18.0-28.7)$ & $20.0(16.3-27.5)$ & 0.003 \\
\hline $\mathrm{SBP}, \mathrm{mmHg}$ & $\begin{array}{l}117(90-147) \\
\text { Page } 10 / 14\end{array}$ & 115 (91-156) & 0.645 \\
\hline
\end{tabular}




\begin{tabular}{|c|c|c|c|}
\hline $\mathrm{DBP}, \mathrm{mmHg}$ & $80(50-114)$ & $78(62-106)$ & 0.227 \\
\hline Pulse rate (beats/min) & $105(67-145)$ & $98(76-145)$ & 0.399 \\
\hline Preoperative $\mathrm{CVP}, \mathrm{cmH}_{2} \mathrm{O}$ & $28.5(18.0-42.0)$ & $26.0(15.5-35.0)$ & 0.029 \\
\hline Pleural effusion & $43(93.5 \%)$ & $44(95.7 \%)$ & 1.000 \\
\hline Ascites & $25(54.3 \%)$ & $24(52.2 \%)$ & 0.834 \\
\hline Pericardial effusion & $38(82.6 \%)$ & $35(76.1 \%)$ & 0.440 \\
\hline LVEF, \% & $58.1(39.9-78.0)$ & $58.0(46.0-72.0)$ & 0.284 \\
\hline Hemoglobin, g/dl & $124(94-167)$ & $122(90-151)$ & 0.239 \\
\hline Albumin, g/L & $33.1(25.1-48.8)$ & $32.1(24.7-45.2)$ & 0.095 \\
\hline Total bilirubin, $\mu \mathrm{mol} / \mathrm{L}$ & $18.1(6.4-66.7)$ & $16.6(4.4-59.2)$ & 0.131 \\
\hline Direct bilirubin, $\mu \mathrm{mol} / \mathrm{L}$ & $10.8(3.2-42.5)$ & $9.1(2.7-50.3)$ & 0.261 \\
\hline Serum sodium, mmol/L & $138.2(126.7-144.5)$ & $\begin{array}{l}137.2(129.5- \\
143.1)\end{array}$ & 0.750 \\
\hline Serum potassium, $\mathrm{mmol} / \mathrm{L}$ & $4.0(2.8-5.1)$ & $3.8(2.7-5.0)$ & 0.881 \\
\hline Preoperative lactate, $\mathrm{mmol} / \mathrm{L}$ & $1.5(0.6-2.7)$ & $1.4(0.5-2.4)$ & 0.865 \\
\hline Preoperative BNP, pg/ml & $181(21-786)$ & $169(21-961)$ & 0.709 \\
\hline Operative duration, $\min$ & $270(140-400)$ & $214(144-390)$ & $<0.001$ \\
\hline Blood loss, ml & $125(40-400)$ & $175(50-800)$ & 0.154 \\
\hline Intraoperative urine output, $\mathrm{mL}$ & $650(50-2000)$ & $700(100-1500)$ & 0.624 \\
\hline \multicolumn{4}{|l|}{ Amount of intraoperative fluid, $\mathrm{ml}$} \\
\hline Total & $1600(700-3100)$ & $2100(1100-3600)$ & $<0.001$ \\
\hline Crystalloid & $1225(600-2600)$ & $1600(1100-3100)$ & 0.064 \\
\hline Colloid & $500(0-500)$ & $500(0-1000)$ & $<0.001$ \\
\hline Blood products & 0 & 0 & / \\
\hline \multicolumn{4}{|c|}{$\begin{array}{l}\text { Intraoperative total fluid infusion rate, } \\
\mathrm{mL} / \mathrm{kg} / \mathrm{h}\end{array}$} \\
\hline $\begin{array}{l}\text { Intraoperative crystalloid infusi } \\
\mathrm{mL} / \mathrm{kg} / \mathrm{h}\end{array}$ & $4.9(2.0-7.5)$ & $7.0(3.9-17.0)$ & $<0.001$ \\
\hline
\end{tabular}


Values presented as $\mathrm{N}$ (percentage) for categorical variables and median (range) for continuous variables.

NYHA, New York Heart Association; COPD, chronic obstructive pulmonary disease; MI, myocardial infarction; $C A D$, coronary atherosclerotic heart disease; PVD, peripheral vascular disease; ASA, American society of anesthesiology; BMI, body mass index; SBP, systolic blood pressure; DBP, diastolic blood pressure; CVP, central venous pressure; LVEF, left ventricular ejection fraction (measured on echocardiogram); BNP, brain natriuretic peptide;

Table 2. Comparison of restrictive and liberal groups on postoperative outcomes

\begin{tabular}{|llll|}
\hline Variables & Restrictive group (N=46) & Liberal group (N=46) & P value \\
\hline Postoperative ICU stay, days & $2(0-6)$ & $3(0-10)$ & 0.178 \\
\hline Postoperative intubation, h & $22.5(0-122.0)$ & $23.0(0-232.2)$ & 0.167 \\
\hline Duration of using vasoactive agents, h & & & \\
\hline Postoperative complications & $0(0-95.0)$ & $1.0(0-144.0)$ & 0.113 \\
\hline Cardiac complications & $10(21.7 \%)$ & $23(50.0 \%)$ & 0.005 \\
\hline Pulmonary complications & $3(6.5 \%)$ & $13(28.3 \%)$ & 0.006 \\
\hline Acute liver or kidney injury & $3(6.5 \%)$ & $7(15.2 \%)$ & 0.180 \\
\hline Duration of chest drainage, days & $3(6.5 \%)$ & $1(2.2 \%)$ & 0.609 \\
\hline Postoperative hospital stay, days & $12(5-27)$ & $12(4-32)$ & 0.853 \\
\hline In-hospital mortality & $14(9-34)$ & $18(7-40)$ & 0.026 \\
\hline
\end{tabular}

Values presented as median (range) for continuous variables and $\mathrm{N}$ (percentage) for categorical variables.

CVP, central venous pressure; BNP, brain natriuretic peptide; ICU, intensive care unit

Table 3. Effect of intraoperative total fluid infusion rate on postoperative outcomes 


\begin{tabular}{|lllllll|}
\hline \multirow{2}{*}{ Groups } & \multicolumn{3}{l}{ Postoperative complications } & \multicolumn{3}{l|}{ Cardiac complications } \\
\cline { 2 - 7 } & OR & $95 \% \mathrm{Cl}$ & P value & OR & $95 \% \mathrm{Cl}$ & P value \\
\hline Restrictive group & 1 & $/$ & $/$ & 1 & $/$ & $/$ \\
\hline Liberal group & 3.551 & $1.192-10.580$ & 0.023 & 5.083 & $1.206-21.426$ & 0.027 \\
\hline
\end{tabular}

$\mathrm{OR}$, odds ratio; $\mathrm{Cl}$, confidence interval

\section{Figures}

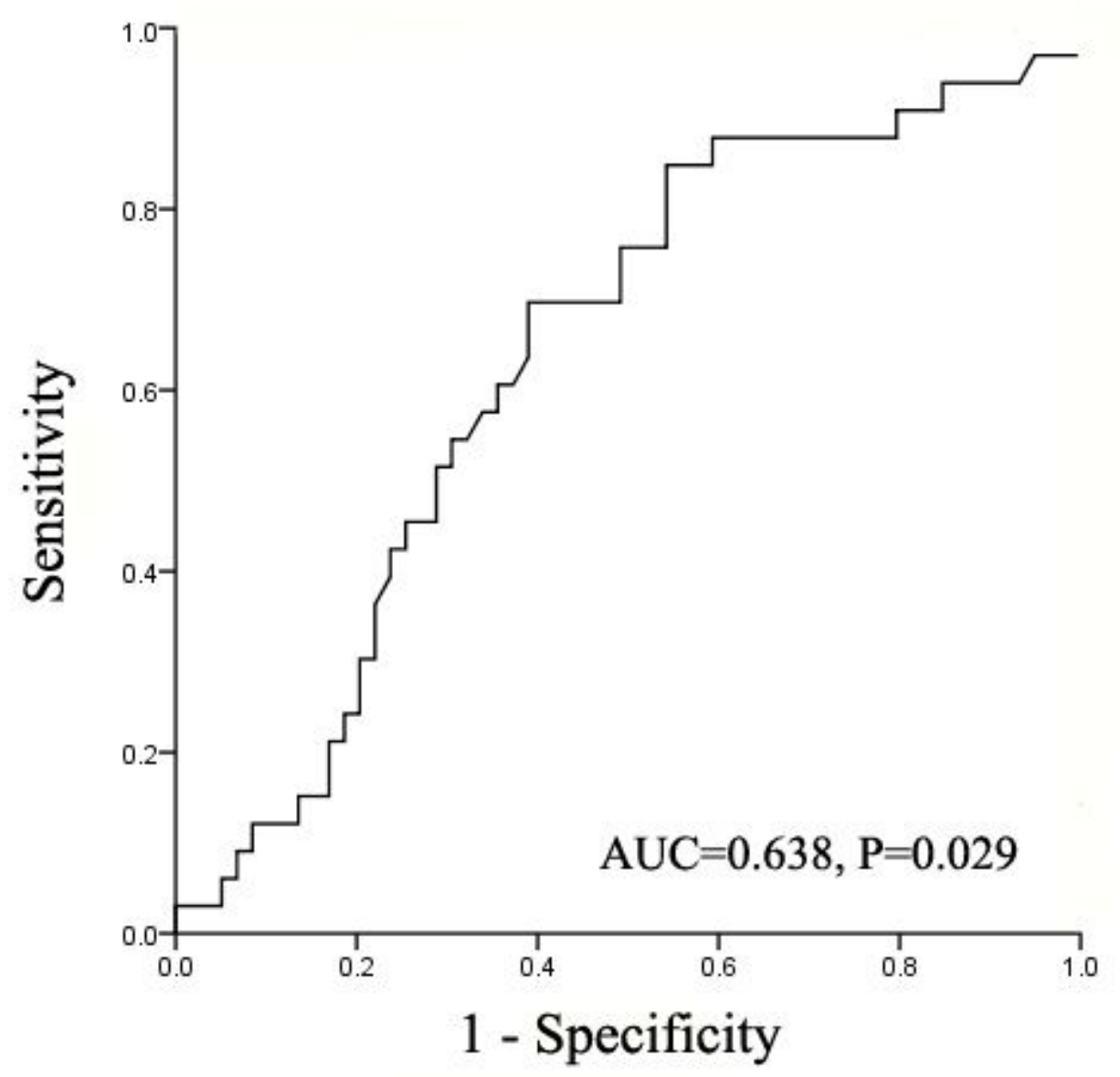

Figure 1

The area under the ROC curve for postoperative complications determined using intraoperative total fluid infusion rate. ROC, receiver operating characteristic; AUC, area under the curve.

\section{Supplementary Files}

This is a list of supplementary files associated with this preprint. Click to download. 
- Supplementaltable.docx

Page 14/14 